\title{
EVALUATION OF INFORMATION CONTENT AND FEATURE EXTRACTION CAPABILITY FROM EGYPT SAT 1 IMAGE
}

\author{
Abdelaal M. Abd Elwahed ${ }^{a}$, Farrag A. Farrag ${ }^{b}$ \\ and Eng. Yasser G. Mostafac \\ ${ }^{a, b}$ Prof. Civil Eng. Dpt. Faculty of Engineering, Assiut University. \\ ${ }^{c}$ Assistant lecturer. Civil Eng. Dpt. Faculty of Engineering, Sohag \\ University.

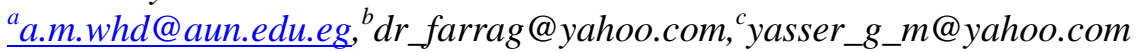

(Received March 27, 2011 Accepted April 26, 2011).

\begin{abstract}
Maps are fast and accurate information sources when it is required, to study and to develop projects in any region. In Egypt, many of the available maps are in an unsatisfactory scale and not updated. The availability of Egypt Sat1 satellite images, opened new possibilities for mapping and map updating. Egypt Satl is the first Egyptian earth observation satellite which was successfully put in orbit in 2007. It captures both multi-spectral and panchromatic images with resolution of 7.8 meters. The main objective of this study is to evaluate the potentials of information content in Egypt Satl images for extracting features in the context of updating of 1:25,000 topographic maps and to ascertain what features could be identified and mapped using visual interpretation techniques supported by supplementary data.

Data used in this study are an image from Egypt Satlsatellite captured in 2009 and a topographic map, dated 1991, at scale 1:25,000 of the region of Assiut city and the surrounding. The investigation in Egypt Sat1 data focused on identification of urban features such as roads, railways, watercourses, bridges and boundaries of urban areas. ERDAS imagine 9.2 software was utilized, where qualitative and quantitative evaluations were performed for the informative content. The research results point to the potential of Egypt Sat1 images as a low cost alternative data source with field verification for the updating of topographic maps at scale 1:25,000.
\end{abstract}

KEYWORDS: Updating, Egypt Sat1, Information Content, Topographic Maps.

\section{INTRODUCTION}

The rate at which maps need updating varies and is related to the rate of development of the area and the types of information contents of the map (Farrag, 1991). There are alternative data sources for map revision and updating, these sources are: ground surveying, aerial photogrammetry and space images. Ground surveying is an accurate technique, however it is expensive and time consuming. Digital photogrammetry are the most adopted technique for city maps production but if there is no photo flight plane available in the country, aerial photogrammetry become time consuming and expensive. The use of remotely sensed data acquired by the satellite images has various 
advantages compared to the other methods such as regular repeat coverage, extensive coverage area and lower costs (Sadeghi, et al. 2004).

Extracting the cultural features from satellite images mainly depends on the information contents of the image data. The topographic information content of the satellite image is a result of many factors, these factors include the spatial, spectral and radiometric resolution of the images (Forghani et al., 2003). There is a strong relationship between spatial and spectral resolution of the images and level of application. Increasing improvement of spatial resolution of remote sensing image creates more information about the objects on the earth (Cengizhan and Sinasi., 2008). So it is important for resource planners to evaluate the capabilities of any sensor to fully understand its potential and the level of applications possible (Gupta and Jain., 2005). Optimal sensors must meet the following criteria for map updating purposes (Forghani, 2002):

1. Appropriate spatial resolution

2. Long operational life and systematic observation

3. Cost effectiveness and accessibility

4. Appropriate ground coverage or swath width

5. Appropriate spectral resolution capability.

The main aim of this study is to represent an evaluation of the topographic information content of Egypt Sat1data for updating of 1:25,000 scale topographic map. The specific aims are:

- Applying enhancement techniques to the satellite image highlighting features of interest; choosing the best final image composition to update 1:25,000 map.

- Updating main map features such as roads, railways, watercourses and boundaries of urban areas.

- Evaluating results in terms of informative content and geometric precision of the final updated map.

\section{METHODOLOGY}

\subsection{Data Acquisition}

Data used in this study are multispectral satellite image from Egypt Sat1 satellite (Figure 1), captured in August 26, 2009, level 1A with $7.8 \mathrm{~m}$ spatial resolution, and topographic map compiled from aerial photographs at 1991 (Figure 2) for Assiut city and the surrounding at scale of 1:25,000. Egypt Sat1 satellite began operation in April 2007, it is a micro-satellite technology built in cooperation with the Ukraine. Egypt Sat1can captures a vertical image for any location in Egypt once every 75 days. It can also be tilted to capture images for location at both sides of satellite path, or re-capture images for location within periods less than 16 days. The space payload for the satellite includes a 4 spectrum optical camera and an infrared camera where their data can be used in different remote sensing applications (NARSS, 2011). The image swath of Egypt Sat1 satellite is $46 \mathrm{~km}$ with the spectral characteristic and ground resolutions as shown in table 1 (Ayman and Ashraf, 2009). 
Table 1: spectral characteristic and ground resolutions of Egyptsat-1

\begin{tabular}{|c|c|c|c|}
\hline Bands & Description & Wave length $(\mu \mathrm{m})$ & Resolution $(\mathrm{m})$ \\
\hline band 1 & Green & $0.51-0.59$ & 7.8 \\
\hline band 2 & Red & $0.61-0.68$ & 7.8 \\
\hline band 3 & Near Infrared & $0.80-0.89$ & 7.8 \\
\hline band 4 & Panchromatic & $0.50-0.89$ & 7.8 \\
\hline band 5 & Mid Infrared & $1.10-1.70$ & 39.5 \\
\hline
\end{tabular}

\subsection{Area of Study}

Governorate of Assiut is one of the oldest governorates in Egypt and it is the capital of Upper Egypt. Its total area is about $25926 \mathrm{~km} 2$. It is situated about $375 \mathrm{Km}$ south of Cairo, the capital of Egypt. Assiut is one of the fastest growing urban areas in Egypt (Farrag and Yasser, 2006).

The Study area has been selected as Assiut city and its surrounding between longitudes $31^{\circ} 79300$ to $31^{\circ} 159000 \mathrm{E}$ and latitudes $27^{\circ} 79300$ to $27^{\circ} 159000 \mathrm{~N}$. Study area contains mixed rural and urban features, it has four major land covers:

1. In the center of the study area, urban area consisting of Assiut city in the center and villages around the city.

2. In the lower-left portion of the study area, desert land.

3. The Nile River extends from the right to the left of the study area and Ibrahimya Canal crossing the Assiut city.

4. Most of the remaining study area is dominated by vegetation surrounding Assiut city and some villages and creates their physical boundaries.

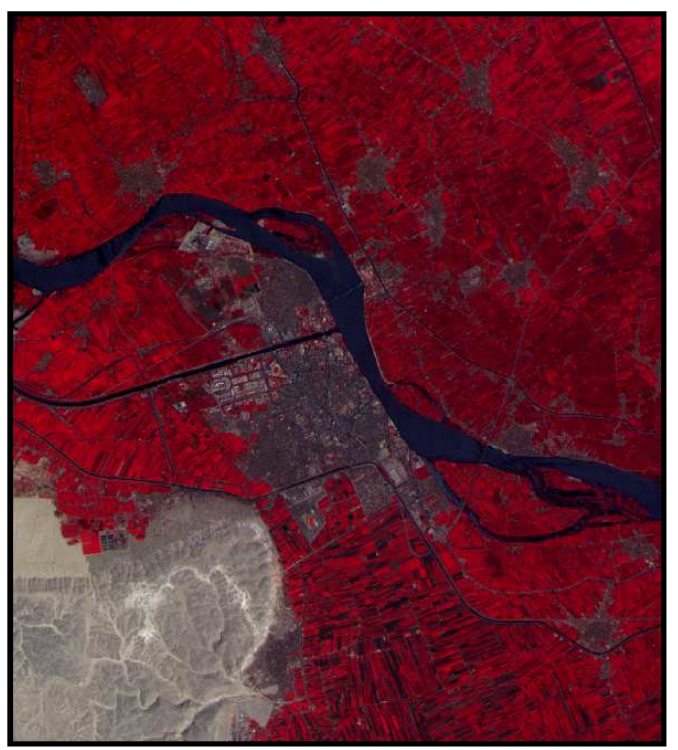

Figure 1: False color composite of August 2009 image for Assiut city and its surrounding.

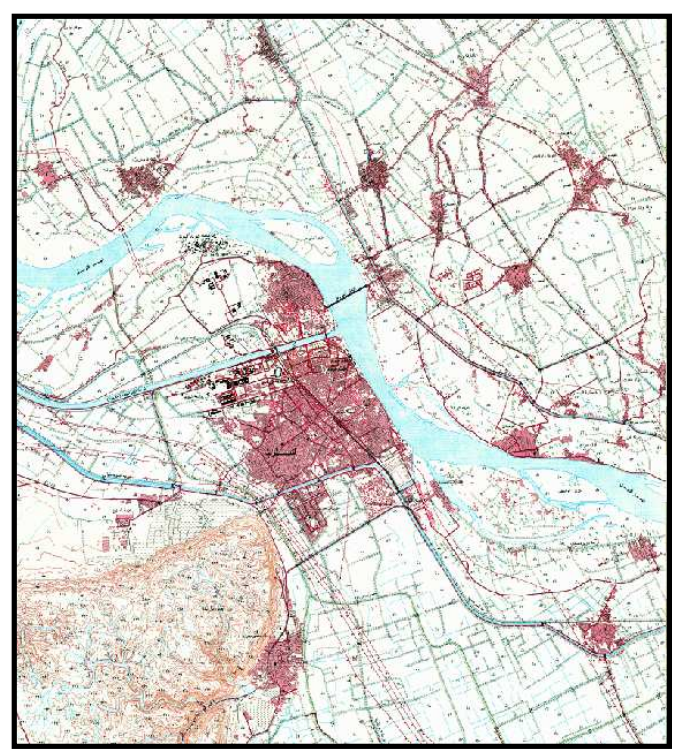

Figure 2: Topographic map 1:25,000 of 1991 for Assiut city and its surrounding. 


\subsection{Image Geo-Referencing}

Before the enhancement of satellite image, the image was geo-referenced to Helmert 1906 projection using a total of 19 Ground Control Points (GCPs). The 19 GCPs and 5 check points were selected to be well distributed and well defined on the image. The coordinates of the GCPs and check points were determined from the 1:25,000 map and field observation applying Global Positioning System (GPS). Second order polynomial transformation was chosen to make the image geo-referencing. The image was rectified with Root Mean Square Error in the check points of $5.59 \mathrm{~m}$.

\subsection{Image Enhancement}

Different enhancement techniques were applied to find image composition to improve the quality of visual interpretation and highlight features of interest. The image was radiometrically enhanced using contrast stretching plus an edge enhancement through a kernel size of 3 by 3 before image interpretation.

\subsection{Visual Interpretation}

Any geoinformation acquisition system is evaluated by the useful information content in the data collected by such a system (Farrag, 1991). The information content of remote sensing images depend upon various factors such as spatial and radiometric resolutions, spatial scale of the features to be imaged, radiometric contrast between different target types, and also the final application for which the images has been acquired (Narayanan, et al. 2002). Urban areas are heterogeneous and complex environments. They represent both natural and human activities. Map and data producers recommend that most feature identification problems are associated with the urban fringe, where rapid change results in uncertainty about the identification of blocks of cleared land or structures such as houses and factories. The expansion of cities and villages in Egypt must be monitored almost annually to control the illegal construction of buildings (Farrag, 1998).

It is important to recognize that the same image may contain different amounts of information depending on the application. To illustrate this point, consider a digital image of a scene containing targets and features of different sizes and extents. Although the spatial resolution of the system may be poor, it may still be useful in identifying those targets and features of interest as long as their sizes are much larger than the sensor spatial resolution. We can then say that the information content of the image for identifying targets and features is high. On the other hand, it may be impossible to identify targets and features of sizes much smaller than the sensor spatial resolution using the same image. In this case, we say that the information content of the image for identifying targets and features of interest is low. Thus, the same image contains high information content for delineating large-sized targets, but low information content for identifying small-sized targets. Choosing an appropriate and meaningful spatial resolution for a particular application is therefore an important task for the remote sensing analyst (Atkinson and Curran 1997).

\subsubsection{Preliminary Verification of Features:}

In preliminary verification, visual analysis of the image with the concomitant display of source material for updated features was done. In practice, a feature should not be 
captured solely from images unless there is some additional supporting information, which confirms the existence of the feature, and provides its attributes. Satellite image is generally used to position new features, and other information is used to attribute the features (Forghani et al., 2003). The following features exist in the study area were considered and evaluated:

\section{Hydrological Features:}

Hydrological features, including rivers, streams, canals and drainage. The delineation of watercourses is an important aspect for urban land-use mapping. Watercourses were well identified (Figure $3 \mathrm{~A}$ ) provided identification and delineation of vegetation area.

\section{Administrative Features:}

Administrative features including buildings, stadium and diesel cisterns, etc. Residential areas, of low density, medium density and high density were selected and analyzed visually. Boundaries of individual buildings can be identified and delineated in low residential areas (Figure $3 \mathrm{~B}$ ) and hazy in medium density (Figure $3 \mathrm{C}$ ). In highdensity areas, there are limitations and it is not possible to identify individual buildings but it can be delineate boundaries of residential area (Figure $3 \mathrm{D}$ ). There are some urban features present in the map which can be identified in the image such as playground in Assiut university (Figure $3 \mathrm{E}$ ), its track and other details are clearly delineated. Diesel cisterns in Wallidia power station (Figure $3 \mathrm{G}$ ) were also clearly delineated.

\section{Communication Lines:}

Communication lines present in study area are roads, railways, etc and associated features e.g. railway stations, bridges, etc. The road network of the city was mapped in two broad categories major roads and secondary roads. There are some distinct characteristics that can be applied in the identification of roads. Minor roads are often built along the length of features such as canals or drainages, which are also visible on image, and allow researchers to gauge the function and importance of a road, if it is required to classify them without additional source material. Background contrast of roads in rural areas is not often as strong as in urban areas. The curvature of the road junctions (Figure $3 \mathrm{~F}$ ) are clear and prominent.

\section{Vegetation Land Cover:}

Most of the study area is dominated by vegetation surrounding the city and villages. Boundaries of vegetation area are often connected to features such as canals and drainages which allow to delineate vegetation fields clearly (Figure $3 \mathrm{H}$ ).

The preliminary updated map was named "Updating Draft". Features with different interpretations are presented in the image and not registered in the map were included in the updating draft for future verification in the fieldwork.

\subsubsection{Final Interpretation and Field Work:}

During the preliminary verification of updated features, fieldwork was done to overcome problems such as misinterpretations and to verify the updated features. The 
aim of this step is to complement the first interpretation with the field reality. The fieldwork offered important information about the verification of roads and railways.

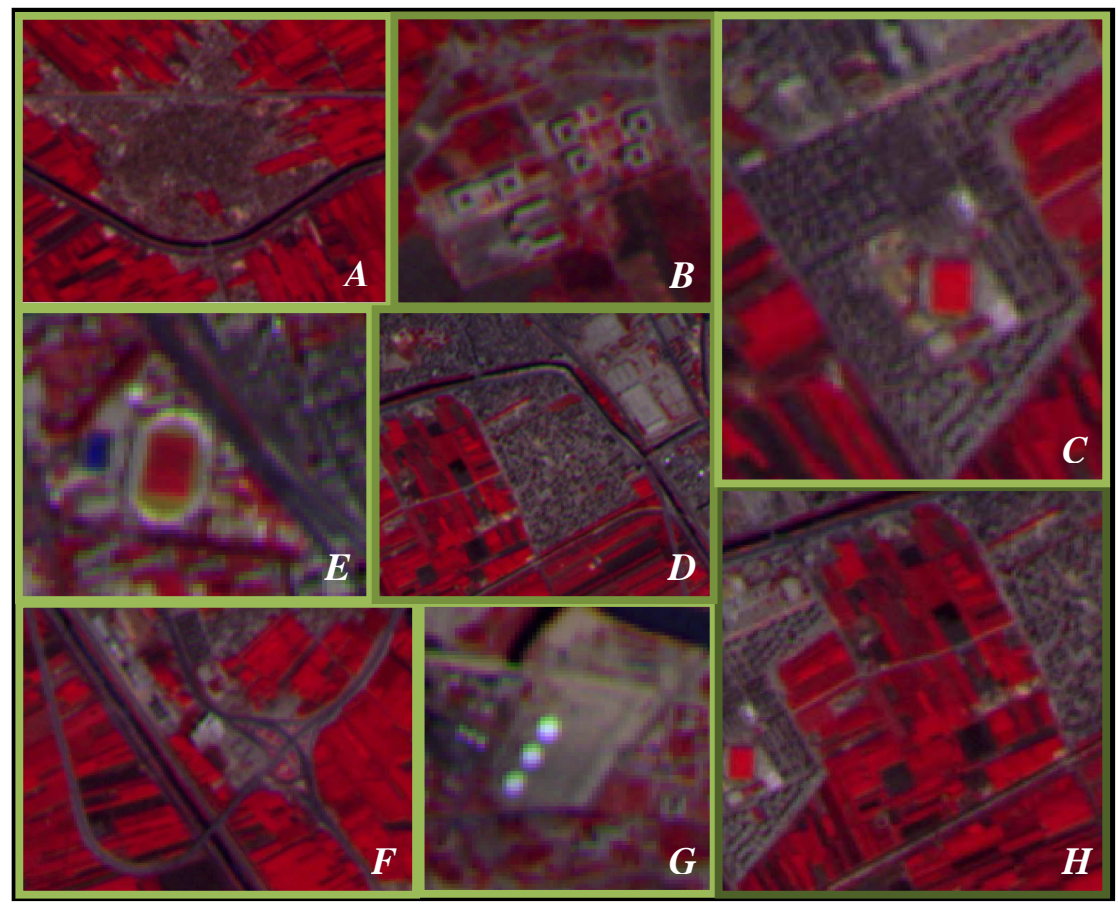

Figure 3: Urban features present in the image. $A$ : water body. $B$ : boundaries of individual buildings in low density residential development. $C$ : Individual building boundaries in the medium density residential area. $D$ : boundaries of high residential area. $E$ : The playgrounds in Assiut university. F: Curvature and junction of roads. $G$ : Diesel cisterns in Wallidia power station. $H$ : boundaries of agricultural fields.

\section{RESULTS AND DISCUSSION:}

As mentioned above the planimetric geometric accuracy of the extracted features from Egypt Sat 1 is about $5.59 \mathrm{~m}$ which can meet the requirement of 1:25,000 map according to the National Map Accuracy Standards (NMAS). Screen digitizing was made through ERDAS imagine 9.2 for linear and polygonal features as shown in figure 4 . The updated map was compared with the original map and the result of comparison are summarized quantitatively in Table 2 .

Table 2: Length and area of features from original map and updated map.

\begin{tabular}{|c|c|c|c|c|}
\hline Features Studied & \multicolumn{2}{|c|}{$\begin{array}{l}\text { Original Topographic Map } \\
\text { Length }(\mathrm{m}) \quad \text { Area }\left(\mathrm{m}^{2}\right)\end{array}$} & \multicolumn{2}{|c|}{ Updated Map } \\
\hline Paved Roads & 201,325 & & 247,868 & \\
\hline Railways & 22,650 & & 22,650 & \\
\hline Watercourses & 414,508 & & 419,044 & \\
\hline Urban Areas & & $8,463,571$ & & $13,741,056$ \\
\hline TOTAL & 638,483 & $8,463,571$ & 689,562 & $13,741,056$ \\
\hline
\end{tabular}


Table 2 shows that resulting map added a large quantity of information to the original map. The comparison between length of roads given in Table 2 shows a significant difference in the extent of the roads, the length of roads from Egypt Sat1 image was $23 \%$ more than that in the map. The increase in length of roads is due to the presence of new roads and changing from some unpaved to paved roads in secondary roads in the last 18 years. Extracting road network outside the urban area is easy compared to that inside the urban area where the contrast between roads and background was relatively low. Major roads and bridges through canals can be delineated precisely (e.g. Figures 4 in red line). About railways, it was noted that this kind of transportation system is almost not changed compared to the map. Extraction of railways can be clearly delineated in vegetation area (e.g. Figures 4 in green line). It was possible to confirm some portions of railways in urban area, while, it was difficult to identify this category in desert and it has been delineated with ground knowledge. The change in the watercourses are comparatively small because the study area is an old vegetation area where the delineated watercourse is $4.5 \mathrm{~km}$ more in length compared to that presented in the map. Watercourses can be presented as polygon feature, such as banks of River Nile, El Ebrahemya Canal and also in small canals such as El Malah Canal (e.g. Figures 4 in pale blue line). Finally, the urban area increased approximately $62 \%$, most of this increase is residential area on expense of vegetation area surrounding cities and villages. Individual buildings are identifiable in this image (e.g. Figures 4 in yellow lines).

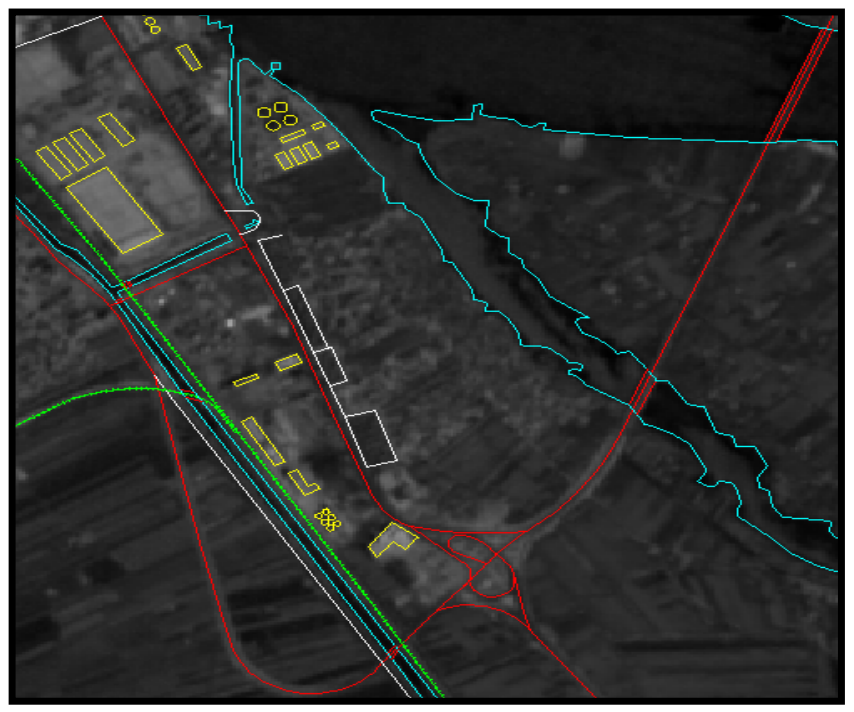

Figure 4: features extracted from EgyptSat-1 imagery. Major roads are shown in red

lines, secondary roads and street networks are shown in white lines, Railways networks are shown in green lines. The banks of the Nile River and El Malah Canal

It is noted that, not all the represented features in the 1:25,000 Egyptian map can be captured from Egypt Sat1 image, such as the overhead power transmission lines and fences. 


\section{CONCLUSIONS AND REMARKS}

The evaluation of the information content and geometric accuracy performed on Egypt sat 1 image showed that, linear features such as roads, watercourses network railways, etc were extracted accurately, except in some places where the contrast between the features and background is relatively low. The roads can be precisely located and updated, which point to a significant increase of the information content in this category. The existent railways were identified except for the extension of railways in desert area which needs field verification to overcome this problem. Watercourse features can be identified and give accurate contribution to the updating process. There were no difficulty to detect and identify boundaries of area features such as high residential area, villages, isolated buildings, boundaries of vegetation area, etc. Features such as overhead power transmission lines were impossible to be detected or identified on the image. Reference material and field work can overcome doubts in the updating process and had a contribution to the final updated map.

The results of this research proved that planimetric accuracy and information content of Egypt Sat1 images are good enough to be used for updating of the main features of Egyptian 1:25,000 maps.

Based on limited testing, it can be concluded that although the Egypt Satlimage appears to offer benefits in interpreting certain features it is desirable that further investigation to be carried out over different landscapes and terrain types to confirm this finding.

\section{REFERENCES}

1- Atkinson, P., Curran, P., 1997 “Choosing an Appropriate Spatial Resolution for Remote Sensing Investigations". Photogrammetric Engineering And Remote Sensing, 63, Pp. 1345-1351.

2- Ayman, H., Ashraf, K., 2009 "Integration of Misrsat-1 and SPOT-2 Data for Quantitative Change Detection Applications". ICGST - International Journal On Graphics, Vision And Image Processing (GVIP) Journal, Volume 9, Issue 5, Pp. 53-59.

3- Cengizhan, I., Sinasi, K., 2008 “Object Identification Using Multi-Resolution Satellite Sensor Images". Proceedings of $29^{\text {th }}$ Asian Conference On Remote Sensing, 10-14 November, Colombo, Sri Lanka.

4- Farrag, A., 1991. "Map Updating Using Digital Techniques with Emphasis on SPOT Images". PhD Thesis, Faculty of Engineering., Assiut University Egypt.

5- Farrag, A., 1998, "Determination of Growth In-Built up Areas and Site Assessment of New Cities Using Satellite Images" Bulletin of the Faculty of Engineering, Assiut University, Vol. 26, No. 2 Pp. 35-45.

6- Farrag, A., Yasser, G., 2006, "Comparison of Land Cover Change Detection Techniques with Satellite Images: Case Study in Assiut, Egypt" Civil Engineering Research Magazine, Al-Azhar University, Volume 28, No.(3) , Pp. 983- 996.

7- Forghani, A., 2002 "Evaluation of KOMPSAT-1 Versus SPOT-2/4 PAN for Maintenance of Geoscience Australia Topographic Databases" In Proceedings 
of The $11^{\text {th }}$ Australasian Remote Sensing and Photogrammetry Conference, 2-6 September, Brisbane, Queensland, Pp. 1-12.

8- Forghani, A., Reddy, R., Smith G., 2003 "Evaluating SPOT-5 Satellite Imagery for National Mapping Division's Topographic Mapping Programs" Proceedings of The Spatial Sciences Conference, September, Canberra, Australia, Pp.1-12.

9- Gupta, K., Jain, S., 2005 "Enhanced Capabilities of IRS-P6 LISS-IV Sensor for Urban Mapping" Current Science, VOL. 89, NO. 11, Pp, 1805-1812.

10- Narayanan, R., Desetty, M., Reichenbach, S., 2002 "Effect of Spatial Resolution on Information Content Characterization in Remote Sensing Imagery Based on Classification Accuracy" International Journal of Remote Sensing, Vol. 23, No. 3, $P p, 537-553$

11- NARSS. "Page Title: Egyptian Space Program" www.narss.sci.eg/Capabilities.aspx, 25 February 2011.

12- Sadeghi, F., Abootalebi, A., Eslami, A., 2004 "Evaluation of The Potential of Spot 5 HRG, High Resolution Satellite Imageries for 1:25000 Scale Maps Revision" The 20th International Congress For Photogermmetry And Remote Sensing, Istanbul, Turkey. 


\section{تقييم محتوى المعلومات وإمكانية استخلاص المعالم من صور القمر الصناعي EGYPT SAT 1}

تعتبر الخرائط من أفضل الوسائل التي يمكن الحصول منها على معلومات لدراسة وتطوير أي منطقة.

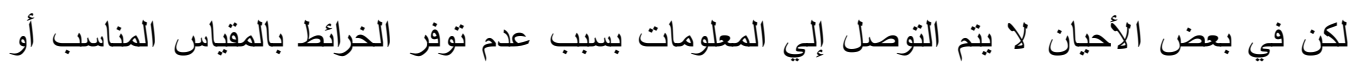

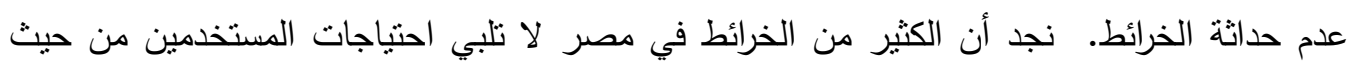
المقياس أو الحداثة. توجد عدة طرق لجمع البيانات بغرض تحديث الخرائط منها المساحة الأرضية، المساحة التصويرية و الاستشعار عن بعد، ويتميز الاستشعار عن بعد عن باقي الطرق بإِكانية

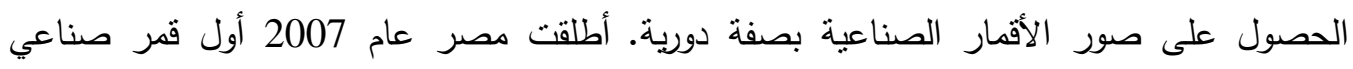
مصري للاستشعار عن بعد Egypt Sat1 مزود بكاميراتي تصوير رقمية إحداها تعمل في مجال

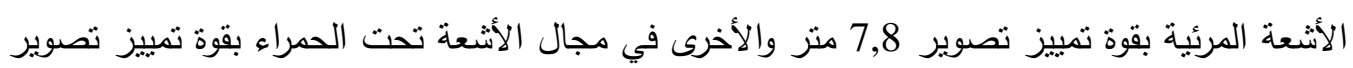
39,5 منر • الغرض من هذا البحث هو تقييم محتوى المعلومات الموجودة في مرئيات القمر الصناعي فئي المصري Egypt Sat1 وما يمكن استخلاصه من بيانات عن أهداف مثل الطرق، السكك الحديدية، المجاري المائية، الكباري، حدود المناطق السكنية وذلك لتحديث الخرائط الطبوغرافية. تم عمل الدراسة باستخدام مرئية ملتقطة بواسطة Egypt Sat1 عام 2009 نوضح مدينة أسيوط وما حولها و كذلك

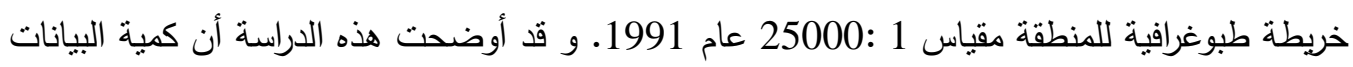
التي أمكن استخلاصها من مرئيات القر الصناعي المصري Egypt Sat1 يمكن استخدامها لتحديث

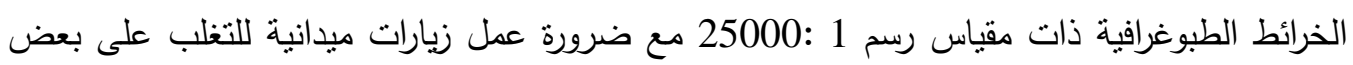
المشاكل في التعرف على بعض التفاصيل. 